\title{
THE RECRUITMENT AND TRAINING OF NURSING STAFF FOR A SPINAL INJURIES UNIT IN AN ACUTE GENERAL HOSPITAL
}

\author{
By John B. Cook, M.D., F.R.C.P. and Evelyn V. SwaN, S.R.N., S.C.M. \\ Spinal Injuries Centre, Pindersfield Hospital, Wakefield, England
}

THE city of Wakefield is situated in the West Riding of Yorkshire. In the thirteenth century, noted for textile industry, it is now almost in the centre of the ten-mile wide 'corridor of coal' which constitutes the North Yorkshire Area of the National Coal Board. There are over 20 collieries within a few miles of the city. New developments in engineering and the mechanisation of coal mining has meant a reduction in the number of mining accidents, and it has had an effect upon employment in the area.

In the grouping of hospitals and implementation of the 'Salmon Report' in 1969, twelve hospitals were amalgamated to form one group in Wakefield. Pinderfields Hospital, which includes the spinal injuries unit, is the largest in the general nursing division. The hospital has a neuro-medical ward of 40 beds, a neurosurgical ward of 33 beds, a neuro-radiological department and a spinal injuries unit of $3 \mathrm{I}$ beds, including both male and female patients. These wards are administered by a nursing officer (grade 7).

The patients on the spinal injuries unit are usually admitted within 24 hours of the injury and are often critically ill. There are approximately 46 new admissions and 60 re-admissions per year. There is undergraduate teaching on the Spinal Injuries Unit for medical students from Leeds University and the consultants concerned with the unit are university lecturers.

This situation presents exceptional opportunities not only for the management of spinal injuries but for the recruitment and training of nursing staff.

The recruitment of hospital staff is influenced by the level of employment in the area. Wakefield has one of the lowest unemployment figures in the country being 2.6 per cent., and although a number of men have been made redundant in the mining industry, their age has been in the region of 50, which is outside the area for the recruitment of nursing staff.

Not many miles from the city, one in eight men may be unemployed, but there are difficulties in their recruitment because of problems with out-of-town transport, particularly its cost. To overcome this, some industries provide their own transport.

In 1965 there were 78 student nurses in training at Pinderfields Hospital Orthopaedic School and this number has gradually fallen to 30, which at present includes only two male students. There has been a particular decline in the recruitment of the I7-I 8 age-group. However, during this period there has been a Io per cent. reduction in the availability of I8-year-olds in the country, and four years ago a pre-nursing course commenced in Wakefield which accommodates many of those young people who, being too young to start nurse training, would have started an orthopaedic course. The proposed reduction in age to $17 \frac{1}{2}$ to start general nurse training may ease this situation. Even so, an orthopaedic nurse in training spends only six weeks in the Spinal Injuries Unit.

Unfortunately the General Nursing Council for England and Wales stipulates that student nurses in general training should not be permitted on the spinal 
injuries unit where orthopaedic training is in force, therefore not only is this field of knowledge closed to them, but upon qualifying their ignorance of this work limits recruitment of trained staff. Limitations are placed upon making good this defect in their training by lack of money to finance post-registration training schemes.

The heavy and sometimes unpleasant aspect of the work has to be borne in mind. To meet the patients' needs it would appear that nursing is necessary at two levels. The acutely ill patient with spinal injury will require the expertise of the trained nurse who has received special education in this sphere, which would include knowledge of intensive nursing care and the apparatus used, for instance, in artificial ventilation of the lungs, care of tracheostomy, occasionally peritoneal dialysis, as well as all the techniques associated with managing a spinal fracture.

No less important is the art of basic nursing care, to assist the patient in the activities of daily living so that he may be as independent as possible. This work requires a patient application to duty and considerable physical stamina. There are special problems relating to the specific techniques of bladder and bowel training, which enable the patient to be socially acceptable.

The management of the acutely ill patient and the administration of the unit requires a person of exceptional ability and a very high standard of skill. The post requires high qualities of leadership and the ability to generate enthusiasm with a zeal for standards of excellence, in an area where the work often appears to be mundane and routine.

It is only in the past two or three years that the state enrolled nurse has found some recognition in the nursing team, and the level at which a state enrolled nurse may take responsibility is not yet clearly defined.

The minutes of the Prices and Incomes Board Report No. 60 (I968) stated:

The Health Department should give guidance on the appropriate range of duties for the enrolled nurse grade. There is much confusion at present about their role in hospitals and a natural reluctance to accept responsibility for entrusting to them activities which could conceivably jeopardise the safety of patients.

Nevertheless, it would appear that the state enrolled nurse has a valuable function in the basic nursing care of a spinal cord paralysis.

The shortage of registered persons available for post-registration training, coupled with the difficulty in training general nurses where orthopaedic nurses are working, and the confusion over the place of the state enrolled nurse, has led to inadequacies in staffing, which has meant that unqualified people have had to be recruited to cover the wide range of duties concerning basic nursing care. This situation, being aggravated by a shortage of money, has led to the employment of auxiliary nurses.

Auxiliary nurses receive two days' induction when newly appointed, designed to give an insight into the life of hospital and a superficial knowledge of emergency procedures. Inadequate though this period may appear to be, it is of great value in preparing the nurse for work in her new environment.

After this the auxiliary nurse is allocated work alongside another nurse on the ward, and there are practical demonstrations and weekly classes covering a syllabus of 42 lectures.

It is necessary to recruit men into the category of ward orderly rather than the auxiliary nursing grade because of the differences of salary structure. A basic minimum salary based on a five-day week between Monday to Friday for day duty 
for a nursing auxiliary is only $£$ I4.I5 per week, whereas a male orderly would receive $£$ I6.72 per week. These men have some interest in hospital work and their duties cover a wider sphere than those of the auxiliary nurse, for instance changing of screen curtains and the cleaning of baths. Often they have been in totally different employment and therefore their ability to carry out basic nursing duties is limited. In spite of this many work in the unit and without them the work would be extremely heavy.

Post-registration courses are necessary to expand the experience which the nurse receives in training for the register or the roll. The Joint Board of Clinical Nursing Studies is examining the various courses available in this country. It will be interesting to know what investigations have been made into the recruitment of staff for post-registration courses in relation to specialised training allocated to the student or pupil nurse. Unless some insight has already been gained by the learner in special fields, fear and lack of knowledge may prevent a nurse moving into a special unit.

To see that the work does not become too arduous, staff must be mentally stimulated. Attendance at study days, courses and conferences where exchange of ideas take place is important. The doctors have a heavy duty in this respect for not only do staff need to know about working in a unit but also about the problems which a patient may have to face in the community. The nurse must see the patient in his home environment.

The General Nursing Council for England and Wales is endeavouring to keep abreast of future developments. As the 1969 syllabus of training is implemented, community care experience will be given to the learner. Already in some areas of the country the learner has the opportunity of gaining experience in domiciliary nursing. A closer relationship with the medical social worker and other staff involved in the rehabilitation of these patients is slowly taking place.

In ensuring the right environment every member must work as part of a team. By instruction and information on individual responsibility, the discipline of self and respect of the skills of all in the team, care of the whole patient is enhanced. Harmonious relationships will ensure that the quality and stardard of care is of the best.

Yet, opportunities of developing only technical and social skills in human relationships leave a vacuum, the danger being that the nurse may become preoccupied with scientific methods to the exclusion of the art of basic nursing care, which remains the most valuable contribution to the well-being of the patient. It is in the spinal unit that a nurse can learn all aspects of illness required for training. The services cover medical, surgical, urology, neurology, psychology, plastic and orthopaedic surgery. Not only this, but the nurse is involved as a vital member of the team in caring for the whole patient, thus teaching the nurse the essence of all aspects and qualities of humanity, thereby making her a 'whole person'.

Before us lies a future of dynamic opportunity with the interchange of nurses between hospital and the community in an Integrated Health Service where new horizons can be envisaged.

\section{REFERENCES}

National Board for Prices and Incomes. Report No. 60: Pay of Nurses and Midwives in the National Health Service. H.M. Stationery Office, March I968, Ch. 6, Para. 79, No. 3 .

Department of Employment and Productivity, Wakefield, Yorks. 